\title{
Téoros
}

Revue de recherche en tourisme

\section{Tourism and National Parks: International Perspectives on Development, Histories and Change, Sous la direction de Warwick FROST et C. Michael HALL Londres, Royaume-Uni : Routledge, 2009, 376 page ISBN-10: 0415471567}

\section{Alain A. Grenier}

Volume 31, numéro 1, 2012

URI : https://id.erudit.org/iderudit/1020719ar

DOI : https://doi.org/10.7202/1020719ar

Aller au sommaire du numéro

Éditeur(s)

Université du Québec à Montréal

ISSN

0712-8657 (imprimé)

1923-2705 (numérique)

Découvrir la revue

Citer ce compte rendu

Grenier, A. A. (2012). Compte rendu de [Tourism and National Parks: International Perspectives on Development, Histories and Change, Sous la direction de Warwick FROST et C. Michael HALL Londres, Royaume-Uni : Routledge, 2009, 376 page ISBN-10: 0415471567]. Téoros, 31(1), 131-131. https://doi.org/10.7202/1020719ar d'utilisation que vous pouvez consulter en ligne. 


\section{POUR EN LIRE PLUS}

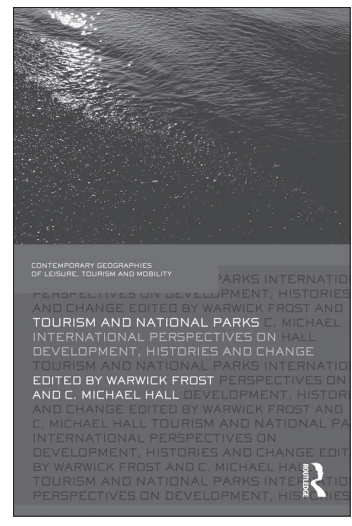

à écrire obtenue auprès d'administrateurs «blancs» de son village. Il complètera son manuscrit à la main, une fois ses rubans d'encre épuisés (le ravitaillement n'était pas automatique dans ces contrées nordiques). Ignorant des formalités du monde de l'édition, il transmet son document à un musée canadien où les conservateurs, croyant à une supercherie, l'entreposent aux oublis. Des années durant, Eddy s'enquerra naïvement du devenir de son "best-seller» auprès des visiteurs de son village. En vain. Jusqu'à ce que Thibault Martin retrace l'ouvrage oublié dans un sous-sol du musée. Avec le soutien d'une avocate, et aux fins d'une bataille juridique, Eddy et Thibault mettent enfin la main sur ce qu'il reste du manuscrit, abîmé par une inondation de la voûte où il était enfermé. Fort d'une longue amitié avec Eddy, Thibault Martin entreprend de compléter les parties effacées du manuscrit, par une lecture de l'ouvrage à son auteur qui livre oralement les passages perdus.

L’ouvrage posthume (Eddy est décédé avant de voir l'œuvre imprimée) constitue aujourd'hui un document incontournable pour comprendre ce que vivent les peuples et les êtres en transition. Thibault Martin complète le livre par un chapitre d'analyse sur la situation de l'identité autochtone que le lecteur canadien, comme étranger, trouvera fort à propos. À travers le récit d'Eddy et ses réflexions sur notre monde de contradictions, le livre propose entre les lignes un message fondamental sur les racines, toutes ethnies confondues, l'importance de les protéger et de les transmettre. «J'espère, écrit Eddy (p. 311), que mon histoire aidera les jeunes à trouver l'inspiration et la force de conserver leur culture, c'est la seule façon de ne pas perdre son âme.»

Best-seller réservé au lectorat francophone, souhaitons que la version originale (qui a été rédigée en anglais) de E9-422 : Un Inuit, de la toundra à la guerre de Corée soit bientôt publiée et qu'elle soit aussi traduite, notamment en inuktitut, afin que ce miroir de fierté et d'ambition soit aussi offert aux contemporains d'Eddy.

\section{Tourism and National Parks: International Perspectives on Development, Histories and Change}

Sous la direction de Warwick FROST et C. Michael HALL

Londres, Royaume-Uni : Routledge, 2009, 376 pages

ISBN-10: 0415471567

Sujet d'intérêt par excellence dans les études en tourisme, le parc national continue d'alimenter la recherche : cela ne devrait pas surprendre puisqu'il est le terrain tout désigné pour la récréation. Apparu pour la première fois en 1872, à Yellowstone (États-Unis), le concept de parc national (parc de la nation) a été adopté ensuite par plusieurs pays qui l'ont adapté selon leurs propre interprétation et leurs besoins. Initialement point de mire de la nation américaine nouvellement indépendante et à la recherche de son identité, le parc national est devenu depuis tantôt un cadre pour la protection de la biodiversité, trop souvent une excuse pour le déplacement (ou l'emprisonnement) de certains, tantôt un outil de développement économique. Faisant appel à une quasi trentaine de chercheurs, cet ouvrage piloté par Warwick Frost et C. Michael Hall propose un tour d'horizon sur l'évolution du concept et de son influence sur le développement du tourisme de nature, à travers le monde.

L'ouvrage propose un regard sur les parcs nationaux selon différentes perspectives. La première partie (cinq chapitres) est consacrée au concept et à la création des parcs nationaux. L'ouvrage propose ensuite des analyses approfondies de perspectives des quatre coins du globe, sur la réalité de création et de gestion des parcs nationaux. La seconde partie de l'ouvrage regroupe cinq chapitres consacrés aux cas du «nouveau monde», en commençant par les États-Unis avec ses parcs fondateurs et deux des géants derrière leur création : John Muir et William Gladstone. Les perspectives canadienne et australienne suivent ensuite. Un chapitre fort intéressant se consacre aux rapports entre les Autochtones et les parcs des milieux où ils vivent.

La troisième partie du livre regroupe les perspectives du «vieux monde» : de l'Espagne à la Suède en passant par le Royaume-Uni. Suit un trio de chapitres présentant des perspectives des pays en développement (Indonésie, Chine et Afrique du Sud). Deux chapitres fort innovateurs dépassent l'objet «nature» pour analyser le rôle culturel du parc, tant en lien avec les Autochtones qu'avec les autres cultures qui y ont développé des marqueurs.

Cet ouvrage, brillamment rédigé, est un incontournable pour quiconque étudie ou travaille sur des thématiques liées au tourisme de nature et les parcs nationaux.

Alain A. GRENIER, Ph. D., Département d'études urbaines et touristiques (ESG-UQAM) 